\title{
Individualizing Therapy for Neovascular Age-Related Macular Degeneration with Aflibercept (VITAL): A Two-Year Prospective, Interventional Single-Centre Trial
}

Praveen J. Patel · Hari Jayaram • Maria Eleftheriadou • Clara Vazquez-Alfageme •

Niaz Islam · Gary S. Rubin • Bishwanath Pal · Peter K. Addison •

Robin Hamilton · Simona Degli Esposti

Received: May 7, 2020 / Published online: June 18, 2020

(C) The Author(s) 2020

\section{ABSTRACT}

Aims: To report the mean change in Early Treatment Diabetic Retinopathy Study (ETDRS) best-corrected visual acuity (BCVA) and reading performance (reading acuity and maximum reading speed (MRS) using the MNREAD test) between baseline and 24 months in treatmentnaïve patients with neovascular age-related macular degeneration (nAMD) treated with intravitreal aflibercept injections.

Methods: A prospective, open-label, interventional non-randomised case series with 24 months' duration. Patients were recruited to the study from medical retina clinics at

Presented at the ARVO Annual Meeting 2019, Vancouver, B.C., Canada.

Digital Features To view digital features for this article go to https://doi.org/10.6084/m9.figshare.12424409.

Electronic supplementary material The online version of this article (https://doi.org/10.1007/s40123020-00267-5) contains supplementary material, which is available to authorized users.

P. J. Patel $(\bowtie) \cdot$ H. Jayaram · M. Eleftheriadou · C. Vazquez-Alfageme · N. Islam · G. S. Rubin . B. Pal - P. K. Addison - R. Hamilton - S. Degli Esposti NIHR Biomedical Research Centre At Moorfields Eye Hospital NHS Foundation Trust, UCL Institute of Ophthalmology, London, UK

e-mail: Praveen.Patel1@nhs.net
Moorfields Eye Hospital. Intravitreal injections of $2.0 \mathrm{mg}$ aflibercept in the study eye were administered using a fixed dosing regimen during the first year and a treat-and-extend treatment regimen during the second year of treatment.

Results: Fifty patients were enrolled with a mean age (SD) of 78.7 (7.6) years; a mean BCVA of 62.8 ETDRS letters; mean reading acuity of $0.52 \log$ MAR; mean maximum reading speed (MRS) of 141.3 words per minute and a central macular thickness of $322.6 \mu \mathrm{m}$ at baseline. The mean improvement in BCVA was 6.4 letters for the 44 patients $(88 \%)$ for whom data was available at 2 years. The mean improvement in reading acuity was $0.13 \log$ MAR with an improvement in MRS of 2.9 words per minute. The mean reduction in CRT from baseline was $104.8 \mu \mathrm{m}$.

Conclusions: Aflibercept treatment of nAMD using fixed dosing in year 1 and treat and extend in year 2 leads to improvements in reading ability, visual acuity and retinal morphology which were maintained to 2 years of treatment.

Trial Registration: ClinicalTrials.gov Identifier NCT02441816, the VITAL study.

Keywords: Aflibercept; Neovascular age-related macular degeneration; Reading ability; Treat and extend 


\section{Key Summary Points}

\section{Why carry out this study?}

Aflibercept is an effective treatment for improving visual acuity in neovascular age-related macular degeneration (nAMD)—one of the commonest causes of vision loss in high-income countries.

Despite effective treatments, little is known about the long-term impact of treatment on reading ability and retinal morphology.

The aim of the study was to report reading ability, visual acuity and retinal morphology outcomes of aflibercept treatment with fixed dosing (year 1) followed by a treat-and-extend treatment paradigm (year 2).

\section{What was learned from the study?}

Sustained improvements in reading ability, visual acuity and retinal morphology can be achieved with aflibercept treatment for wet AMD using fixed dosing in year 1 followed by a proactive, treat-and-extend treatment paradigm in year 2 .

As one of the primary goals of wet AMD treatment from a patient perspective is improving or restoring reading ability, future wet AMD clinical trials should include reading-related outcome measures to better help understand the impact of treatment on vision function.

\section{INTRODUCTION}

The past decade has seen dramatic advances in treatments for neovascular age-related macular degeneration (nAMD) due to the introduction of agents which block the action of vascular endothelial growth factor (anti-VEGF agents) into clinical practice. The licensing of aflibercept for nAMD followed successful visual acuity outcomes in two double-masked phase III clinical trials (the "VEGF Trap-Eye: Investigation of Efficacy and Safety in Wet AMD"-VIEW 1 and VIEW 2 studies) [1]. These trials used a bimonthly treatment paradigm in the first year after an initial course of three injections, each given a month apart. In the second year, a capped pro re nata (PRN) treatment strategy was used, with patients being reviewed every month. In an effort to maximise efficacy, while minimising the number of clinic visits in elderly patients with nAMD, a 'treat and extend' approach to treatment has gained favour with ophthalmologists with successful outcomes recorded in a number of 'real world' retrospective as well as prospective studies [2-6]. Though treat-and-extend treatment paradigms can vary in their detail, the central guiding principle is to carry out an anti-VEGF injection at every visit and to increase or decrease the interval between injections to minimise recurrence of nAMD disease activity.

Despite the popularity of treat and extend, little is known about the impact of aflibercept treat-and-extend treatment paradigms on additional functional outcomes relating to reading performance and optical coherence tomography (OCT) imaging metrics relating to retinal morphology and choroidal thickness. Reading ability is a complex, vision-based process which is complementary to distance, high-contrast visual acuity and contrast sensitivity as an important additional measure of vision function in patients with nAMD. Indeed, reading speed influences the ability of patients to perform everyday tasks independently $[7,8]$ and correlates better to vision-related quality of life than high contrast distance visual acuity [9]. Despite the importance of the ability to read for patients with nAMD [10] there have been, to the best of our knowledge, no prospective trials reporting reading performance as an outcome measure in aflibercept treatment of nAMD. The aim of the phase IV individualizing therapy for nAMD with aflibercept (VITAL) study was to evaluate effectiveness of a fixed dosing aflibercept treatment regimen in year 1 and a treatand-extend treatment regimen in year 2 in patients with nAMD on reading ability, visual 
acuity and OCT-derived measures of retinal morphology. This report describes the 24-month results of the VITAL study.

\section{METHODS}

The VITAL study was a 24-month, prospective, open-label, uncontrolled phase IV study (ClinicalTrials.gov Identifier NCT02441816, the VITAL study). It was conducted in accordance with the tenets of the Declaration of Helsinki and ethics approval was obtained from the NRES (National Research Ethics Service) Committee London Fulham (approval number 14/LO/1561; EudraCT number 2014-00238173). Although patients were not directly involved in the development of the research study, the objectives of the VITAL study are aligned with the research uncertainties identified by the James Lind Alliance Sight Loss and Vision Priority Setting Partnership workshop. This was a single-centre study conducted at Moorfields Eye Hospital NHS Foundation Trust. All participants provided written informed consent.

\section{Participants}

The study population consisted of patients aged 50 years or over with symptomatic, previously untreated, nAMD in the study eye, with a bestcorrected visual acuity (BCVA) of between 23 and 80 Early Treatment Diabetic Retinopathy Study (ETDRS) letters (approximately 6/7.5 to $6 / 96$ Snellen equivalent). For inclusion in the study, the choroidal neovascular membrane should show signs of disease activity (leakage on fundus fluorescein angiography (FFA) and intraretinal or subretinal pigment epithelial fluid on OCT imaging) with foveal involvement. Detailed inclusion and exclusion criteria are listed in the supplementary file (Supplementary Table 1 ).

\section{Treatment}

All eligible participants were treated with aflibercept intravitreal injection $(2.0 \mathrm{mg} /$ $0.05 \mathrm{ml}$ ).

Treatment was administered at baseline, month 1 and month 2 (three treatments, each a month apart) and then every 2 months for a further five injections. In the second year of treatment, a treat-and-extend treatment paradigm (capped at 12 weeks) was used until the end of year 2. Specifically, treatment intervals in year 2 were extended by 2 weeks if there was no macular fluid on OCT, or, reduced by 2 weeks if there was macular fluid or new macular haemorrhage. In the presence of intra- or subretinal fluid on OCT imaging at any visit, intervals were shortened to 8 weeks. The pattern of visits in year 2 varied depending on the response to treatment and the total number of study visits therefore varied from 12 to 14 for the cohort over 96 weeks (with the final study visit occurring at week 100 for some patients and 94 weeks for others).

\section{Study Objectives}

To assess whether intravitreal aflibercept administration using fixed dosing in year 1 followed by a capped treat-and-extend treatment paradigm in year 2 (capped at a treatment interval of 12 weeks) was associated with improved reading ability and BCVA in eyes with active nAMD over 2 years.

\section{Efficacy Assessments}

These included both functional (BCVA and reading ability) and structural (multimodal imaging including FFA, indocyanine green (ICG) angiography, spectral-domain and sweptsource OCT imaging) assessments. The OCT, FFA and ICG images were assessed and analysed by the clinical trial investigators working on the study. FFA and ICG angiography were preformed at baseline, 1 year and 2 years. Distance visual acuity was measured using ETDRS charts. Reading acuity and reading speed were assessed using MNREAD acuity charts. The MNREAD 
charts used in this study were developed at the Minnesota Laboratory for Low-Vision Research. They are used in clinical trials and clinical practice to assess reading performance. A reading speed of 80 words per minute (wpm) has been suggested as the minimum needed to support fluent reading [11]. A previous study of the repeatability of reading metrics in patients with AMD showed that a reading acuity change of $0.30 \log$ MAR or more is indicative of meaningful clinical change (rather than measurement variability) with a change of $77 \mathrm{wpm}$ or more in maximum reading speed (MRS) indicating meaningful clinical change [12]. We chose these thresholds as end points in the VITAL study.

\section{Safety Assessments}

Adverse events were assessed at each visit and serious adverse event and suspected unexpected serious adverse reactions were recorded and reported.

\section{Statistics Methodology}

This was an exploratory study and therefore all outcomes are presented as descriptive statistics. For any qualitative data, proportions and frequencies were calculated, and for any quantitative data, means, standard deviation, median and interquartile ranges were presented as appropriate. The 95\% confidence intervals were also calculated where relevant. All analyses were conducted using STATA 14.0.

\section{RESULTS}

\section{Patient Demographics and Baseline Characteristics}

Between 24 November 2014 to 17 March 2016, 103 patients were assessed for eligibility. Sixtyeight of them met the inclusion criteria and 50 of them were enrolled in the study. One patient, who withdrew consent very early on in the study, was not treated as per protocol up until 1 year but had the 1-year assessment visit. It was

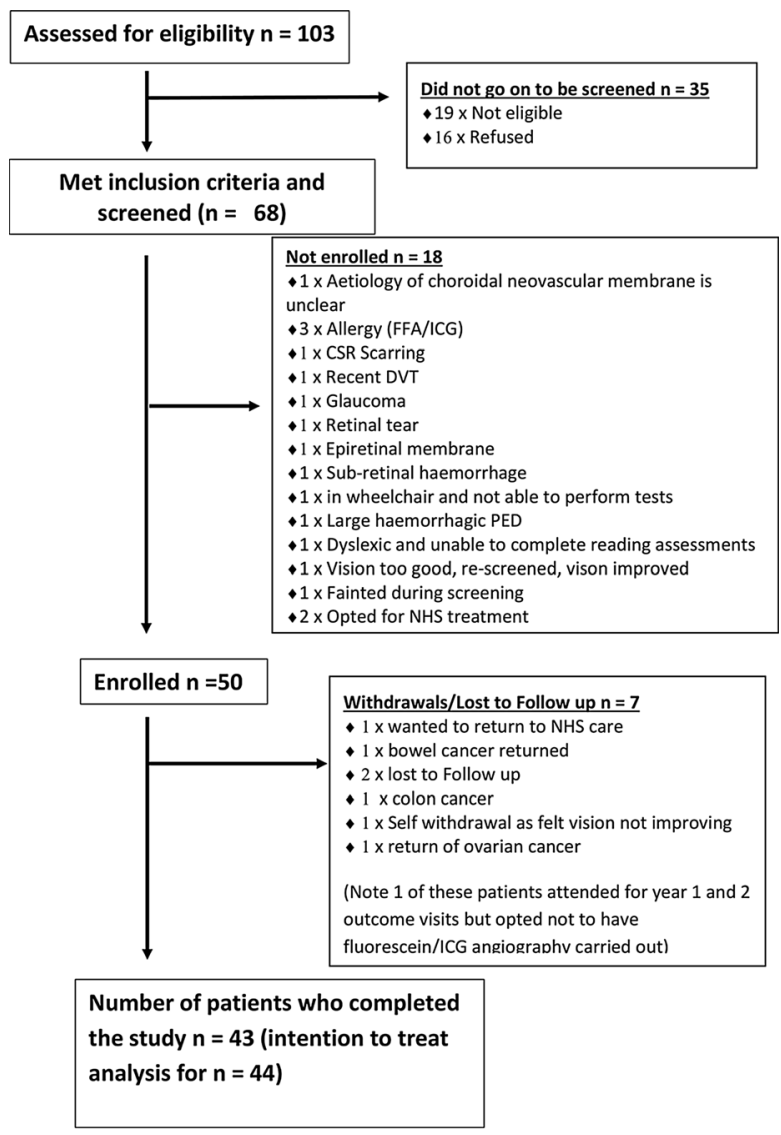

Fig. 1 CONSORT flow chart

agreed at the Trial Steering Committee meeting to include this patient in the main analysis (intention to treat analysis) and a sensitivity analysis (per protocol analysis) to be conducted excluding this patient. The relevant CONSORT flow chart is presented in Fig. 1.

Of the 44 participants completing 2-year follow-up, there were 31 female patients $(70 \%)$ and 13 male patients (30\%). Forty-one study participants $(93 \%)$ were white Caucasian with a mean (SD) age of 78.9 (7.2) years. Non-ocular baseline characteristics are included in Table 1.

\section{Visual Acuity and Reading Ability Outcomes}

At baseline, the mean and median BCVA letter scores were 62.8 and 65 , respectively. The mean and median BCVA improved by 6.4 letters and 8 letters respectively, with a mean and median 
Table 1 Non-ocular baseline characteristics

\begin{tabular}{lll}
\hline & $\begin{array}{l}\text { Participants enrolled } \\
\text { in study }(\boldsymbol{N}=\mathbf{5 0})\end{array}$ & $\begin{array}{l}\text { Participants completing 2-year } \\
\text { follow-up }(\boldsymbol{N}=\mathbf{4 4})\end{array}$ \\
\hline $\begin{array}{l}\text { Number of patients } \\
\text { (Eyes), } n(\%)\end{array}$ & $50(100)$ & $44(100)$ \\
Gender & $15(30) / 35(70)$ & $13(30) / 31(70)$ \\
Male/female, $n(\%)$ & & \\
Age (years) & $78.7(7.6)$ & $78.9(7.2)$ \\
Mean (SD) & & $41(93)$ \\
Ethnicity, $n(\%)$ & $46(92)$ & $1(2)$ \\
White & $2(4)$ & $1(2)$ \\
Asian & $1(2)$ & $1(2)$ \\
Mixed & $1(2)$ & \\
Other & &
\end{tabular}

improvement in reading acuity of $0.13 \log$ MAR and $0.18 \log$ MAR respectively at the 2 -year follow-up. Mean and median reading speed improved by 2.9 and $5.5 \mathrm{wpm}$ respectively at the 2-year follow-up.

\section{Optical Coherence Tomography and Fundus Fluorescein Angiography Outcomes}

The mean and median Spectralis OCT central $1 \mathrm{~mm}$ subfield retinal thickness were markedly reduced by year 2 as were the mean and median lesion areas (Table 2). At the end of year 2, 39\% of all patients showed no leakage on FFA. These outcomes were achieved with a median (IQR) of $12(11,13)$ injections over a median (IQR) of 13 $(12,15)$ study visits. Baseline and 2-year treatment outcomes are presented in Table 2 .

All continuous variables were skewed at baseline and year 2; however, the changes from baseline to year 2 for all were normally distributed. The mean (SD) has been presented as well as the median (IQR) for the results at baseline and 2-year for comparison with the mean change. Change in BCVA, CRT, reading speed and reading acuity throughout the first year are displayed in Fig. 2.

\section{Pre-specified Exploratory Outcomes}

Seven of the 50 patients initially included in the trial $(14 \%)$ had polypoidal choroidal vasculopathy (PCV) and six patients (12\%) had a retinal angiomatous proliferation (RAP) lesion on the basis of multimodal imaging including ICG angiography.

One patient who withdrew early from the study was not included in the exploratory analysis regarding the presence of subretinal hyperreflective material (SHRM) and measurement of maximum retinal pigment epithelial detachment (PED) height (therefore the total number of patients included in the analysis was $n=45$ ). All eyes had evidence of macular fluid on OCT imaging at baseline with 36 eyes (80\%) having evidence of SHRM. At the 2-year followup visit, 24 eyes (55\%) had no macular fluid; 10 eyes (23\%) had evidence of SHRM. Thirty-nine eyes of the 44 included in the 2-year analysis (89\%) had a PED as a lesion component at baseline. The median maximum PED height was $307 \mu \mathrm{m}$ at baseline in these 39 eyes reduced to $190 \mu \mathrm{m}$ at 2 years. We performed data analysis regarding the median values, lower and upper quartiles at each visit of maximum PED height. A graphic display in the form of a box 
Table 2 Visual acuity, reading performance and retinal morphology-related treatment outcomes at 2 years $(N=44)$

\begin{tabular}{|c|c|c|c|c|}
\hline & Baseline & Year 2 & $\begin{array}{l}\text { Change } \\
\text { from } \\
\text { baseline }\end{array}$ & $\begin{array}{l}95 \% \text { CI for mean } \\
\text { change from } \\
\text { baseline }\end{array}$ \\
\hline \multicolumn{5}{|l|}{ ETDRS BCVA } \\
\hline Mean (SD) & $\begin{array}{l}62.8 \\
\quad(12.8)\end{array}$ & $\begin{array}{l}69.2 \\
\quad(16.2)\end{array}$ & $6.4(11.7)$ & $2.9,10.0$ \\
\hline Median (IQR) & $\begin{array}{c}65(55.5 \\
74)\end{array}$ & $\begin{array}{r}73(62 \\
80.5)\end{array}$ & & \\
\hline \multicolumn{5}{|c|}{ Number of hospital visits over 2 years } \\
\hline Median (IQR) & - & $\begin{array}{c}13(12, \\
15)\end{array}$ & - & - \\
\hline \multicolumn{5}{|c|}{ Number of aflibercept injections over 2 years } \\
\hline Median (IQR) & - & $\begin{array}{c}12(11, \\
13)\end{array}$ & - & - \\
\hline \multicolumn{5}{|c|}{ Reading speed (wpm) } \\
\hline Mean (SD) & $\begin{array}{r}141.3 \\
(53.3)\end{array}$ & $\begin{array}{l}144.2 \\
(65.5)\end{array}$ & $2.9(60.8)$ & $-15.6,21.4$ \\
\hline Median (IQR) & $\begin{array}{l}150 \\
(113, \\
183)\end{array}$ & $\begin{array}{l}155.5 \\
(103.5, \\
200)\end{array}$ & & \\
\hline \multicolumn{5}{|c|}{ Reading acuity (logMAR) } \\
\hline Mean (SD) & $\begin{array}{l}0.52 \\
\quad(0.32)\end{array}$ & $\begin{array}{l}0.39 \\
\quad(0.41)\end{array}$ & -0.13 & $-0.21,-0.04$ \\
\hline Median (IQR) & $\begin{array}{l}0.46 \\
(0.31 \\
0.65)\end{array}$ & $\begin{array}{l}0.28 \\
(0.12 \\
0.50)\end{array}$ & $(0.28)$ & \\
\hline \multicolumn{5}{|c|}{ Macular thickness on OCT $(\mu \mathrm{m})$} \\
\hline Mean (SD) & $\begin{array}{l}322.6 \\
\quad(88.1)\end{array}$ & $\begin{array}{l}226.3 \\
(57.2)\end{array}$ & -104.8 & $-137.6,-72$ \\
\hline Median (IQR) & $\begin{array}{l}304.5 \\
(260 \\
390)\end{array}$ & $\begin{array}{l}210.5 \\
(192.5 \\
253)\end{array}$ & $(97.0)$ & \\
\hline Missing, $n(\%)$ & $2(5)$ & $8(18)$ & $8(18)$ & \\
\hline \multicolumn{5}{|c|}{ Choroidal thickness on OCT $(\mu \mathrm{m})$} \\
\hline Mean (SD) & $\begin{array}{l}205.7 \\
\quad(104.4)\end{array}$ & $\begin{array}{l}175.3 \\
(82.2)\end{array}$ & $\begin{array}{r}-29.2 \\
(90.2)\end{array}$ & $-59.7,-1.4$ \\
\hline
\end{tabular}


Table 2 continued

\begin{tabular}{lcccc}
\hline & Baseline & Year 2 & $\begin{array}{l}\text { Change } \\
\text { from } \\
\text { baseline }\end{array}$ & $\begin{array}{l}\text { 95\% CI for mean } \\
\text { change from } \\
\text { baseline }\end{array}$ \\
\hline Median (IQR) & 186 & 163.5 & -15.5 \\
& $(134$, & $(114$, & $(-61.9)$ \\
Missing, $n(\%)$ & $258)$ & $233.5)$ & \\
\hline
\end{tabular}

Proportion of study eyes with BCVA improvements between baseline and year 2 of

$\geq 5$ letters, $n(\%)$

$\geq 10$ letters, $n(\%)$

$\geq 15$ letters, $n(\%)$
$24(55)$

$16(36)$

$12(27)$

Number of study eyes (\%) with BCVA loss between baseline and year 2 of

$$
\begin{aligned}
& \geq 5 \text { letters, } n(\%) \\
& \geq 10 \text { letters, } n(\%) \\
& \geq 15 \text { letters, } n(\%)
\end{aligned}
$$

Number of study eyes (\%) with BCVA change in study eye of $\leq 4$ letters between baseline and year $2, n(\%)$

Number of study eyes (\%) with reading acuity gain of $>0.3$ between baseline and year $2, n(\%)$

Number of study eyes (\%) with reading acuity loss of $>0.3 \log$ MAR between baseline and year $2, n(\%)$

Number of study eyes (\%) with reading speed increase of $>77 \mathrm{wpm}$ between baseline and year $2, n(\%)$

Number of study eyes (\%) with reading speed loss of $>77 \mathrm{wpm}$ between baseline and year 2, $n$ (\%)

Number of study eyes (\%) with leak on FFA in the study eye, at the 2-year follow-up visit, $n$ (\%)

Number of study eyes (\%) with no leak on FFA in the study eye, at the 2-year follow-up visit, $n$ (\%)

Missing, $n(\%)$

$$
-\quad 2(5)
$$

FFA-based measurement of lesion size $\left(\mathrm{mm}^{2}\right)$
Mean (SD)
6.66
6.79
$1.0(5.40)$
$-0.68,2.68$
(8.32)
Median (IQR)
$4.22 \quad 5.0(2.5$,
$(2.75, \quad 8.6)$
$7.04)$
Missing, $n$ (\%)
$0(0) \quad 2(5) \quad 2(5)$ 
Table 2 continued

\begin{tabular}{lcccc}
\hline & Baseline & Year 2 & $\begin{array}{l}\text { Change } \\
\text { from } \\
\text { baseline }\end{array}$ & $\begin{array}{l}\text { 95\% CI for mean } \\
\text { change from } \\
\text { baseline }\end{array}$ \\
\hline FFA-based measurement of CNV size $\left(\mathrm{mm}^{2}\right)$ & & & & \\
Mean (SD) & 1.66 & 0.57 & -0.76 & $-1.15,-0.37$ \\
Median (IQR) & $(2.64)$ & $(0.97)$ & $(1.26)$ & \\
& $1.09(0.7,0.16(0$, & & \\
Missing, $n(\%)$ & $1.9)$ & $0.54)$ & & \\
\hline
\end{tabular}

$B C V A$ best corrected visual acuity, $S D$ standard deviation, $I Q R$ interquartile range, $w p m$ words per minute, $\log M A R$ logarithm of minimum angle of resolution, $F F A$ fundus fluorescein angiogram, $C N V$ choroidal neovascular membrane

plot of the maximum PED height over the course of 2 years is included in the supplementary file (Supplementary Fig. 1). BCVA, reading speed and reading acuity change associated with the presence or absence of subretinal/intraretinal fluid at the end of year 2 are also shown in Table 3.

\section{Safety}

There were 16 serious adverse events (SAEs) and one suspected unexpected serious adverse reaction (SUSAR) as listed in the supplementary file (Supplementary Table 2). The SUSAR was a stroke which was possibly related to the study drug. All SAEs were recorded as not related to treatment in the trial.

\section{DISCUSSION}

The results of the VITAL study show that sustained, long-term improvements in reading performance and BCVA are achieved at 2 years in nAMD eyes treated with aflibercept using fixed dosing followed by a treat-and-extend treatment paradigm. Indeed, the proportion of eyes avoiding moderate vision loss, with a visual acuity loss of less than 15 letters at the end of year 1 was $95 \%$, the same proportion as in the aflibercept treatment arms of the VIEW 1 and VIEW 2 trials [1].

Quality of life is directly associated with visual ability, and reading performance predicts what patients report as visual ability [13]. Reading ability is a treatment outcome which patients can relate to and the ability to read fluently is often a treatment goal for patients with nAMD.

Clinical trials of anti-VEGF treatment of wet AMD using treat-and-extend treatment regimens have used functional end points based on distance visual acuity and have not considered the impact of treatment on reading ability. Our study shares some similarities to the work reported by Epstein and Amren [14]. Both studies show an improvement in visual acuity and reading acuity with intravitreous aflibercept treatment for wet AMD. However, ours was a prospective study with 2-year follow-up which included an assessment of reading speed whereas the report by Epstein and Amren [14] was a retrospective study for 18 months carried out in a clinic setting and which did not include an assessment of reading speed. A better understanding of the impact of anti-VEGF therapy on reading performance would help clinicians to offer patients a richer perspective into what patients may expect in terms of vision function and quality of life with long-term 

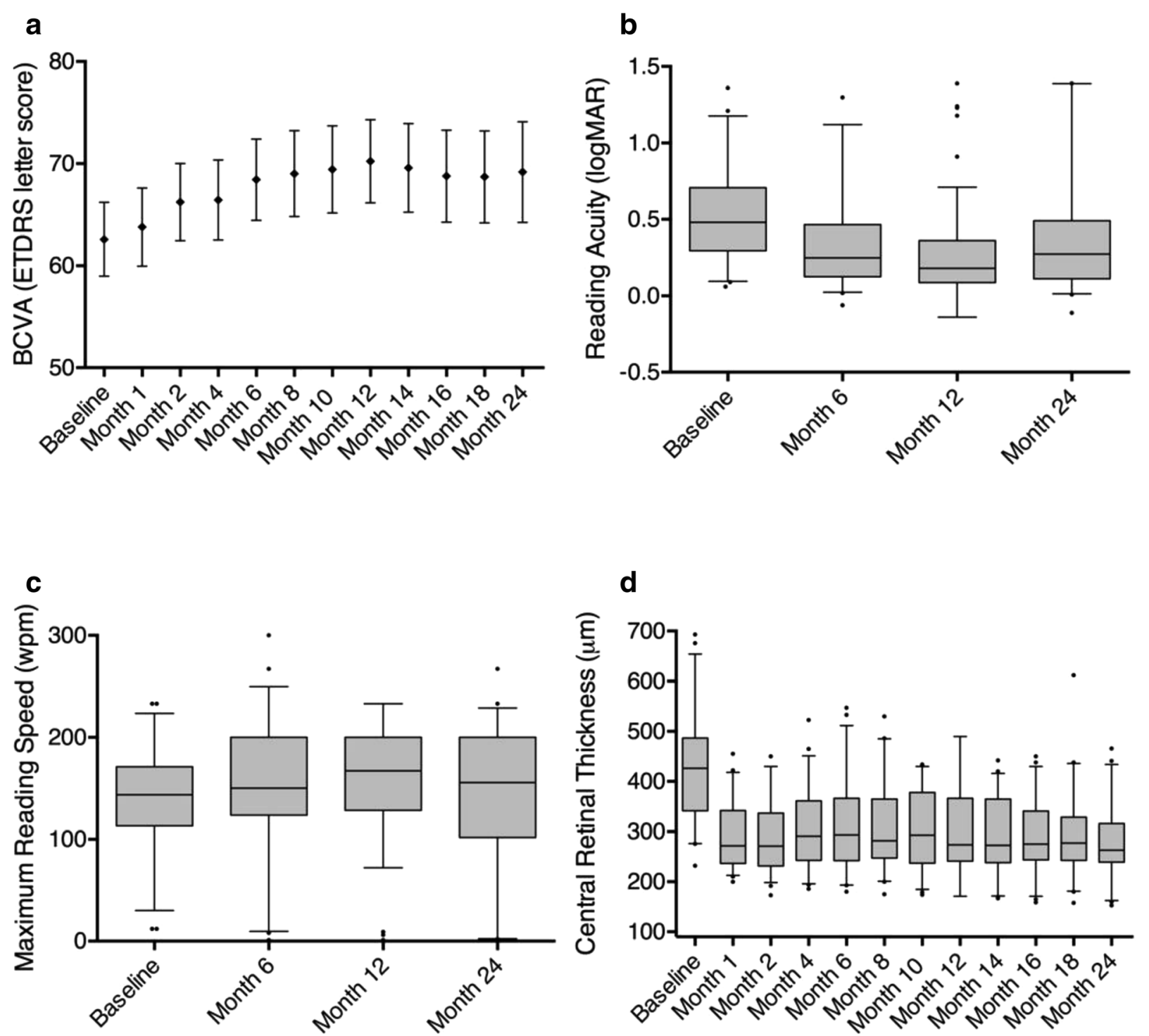

Fig. 2 Changes in a BCVA, $\mathbf{b}$ reading acuity, $\mathbf{c}$ reading speed and $\mathbf{d}$ CRT from baseline to 24 months

treatment for nAMD. In our study, reading acuity loss of greater than $0.3 \log$ MAR between baseline and year 1 was observed in only $5 \%$ of the eyes included. Reading speed loss of greater than 77 wpm between baseline and year 1 was observed only in $9 \%$. Therefore, reading acuity and reading speed were preserved in $95 \%$ and $91 \%$ of 279 the eyes treated in the VITAL study at year 2. The modest gain in MRS can be explained on the basis of high baseline reading ability of the patients leading to a ceiling effect for further improvement. Currently, there are no standard-treatment 'success rates' regarding preservation of reading ability for anti-VEGF treatment. Reading acuity results in this study, and the methods used to assess them, can be used to compare outcomes of future clinical trials if reading performance is included as an outcome measure.

In terms of OCT-based changes in retinal morphology and thickness, we report a mean central macular thickness reduction of $104.8 \mu \mathrm{m}$ at 2 years from baseline comparable to $116.5 \mu \mathrm{m}$ or $128.5 \mu \mathrm{m}$ in the VIEW 1 and 
Table 3 Visual acuity and reading performance in study eyes with and without macular fluid at 2 years

\begin{tabular}{|c|c|c|c|c|}
\hline $\begin{array}{l}\text { Intraretinal/subretinal } \\
\text { fluid at year } 2\end{array}$ & Baseline & Year 2 & $\begin{array}{l}\text { Mean change } \\
\text { from baseline }\end{array}$ & $\begin{array}{l}95 \% \text { CI for mean } \\
\text { change from baseline }\end{array}$ \\
\hline \multicolumn{5}{|c|}{ Best corrected visual acuity (ETDRS letter score) } \\
\hline \multicolumn{5}{|l|}{ No $(n=24)$} \\
\hline Median (IQR) & $64.5(52,75)$ & $71.5(57,81)$ & & \\
\hline Mean (SD) & $61.0(13.5)$ & $67.2(18.4)$ & $6.1(11.7)$ & $(1.2,11.1)$ \\
\hline \multicolumn{5}{|l|}{ Yes $(n=20)$} \\
\hline Median (IQR) & $67.5(58,75)$ & $73.5(66,81)$ & & \\
\hline Mean (SD) & $64.9(11.8)$ & $71.6(13.3)$ & $6.8(11.8)$ & $(1.2,12.3)$ \\
\hline \multicolumn{5}{|l|}{ Reading acuity (logMAR) } \\
\hline \multicolumn{5}{|l|}{ No $(n=24)$} \\
\hline Median (IQR) & $0.52(0.31,0.65)$ & $0.31(0.12,0.86)$ & $-0.10(0.29)$ & $(-0.22,0.03)$ \\
\hline Mean (SD) & $0.56(0.35)$ & $0.46(0.47)$ & & \\
\hline \multicolumn{5}{|l|}{ Yes $(n=20)$} \\
\hline Median (IQR) & $0.39(0.29,0.66)$ & $0.23(0.09,0.43)$ & & \\
\hline Mean (SD) & $0.47(0.29)$ & $0.30(0.31)$ & $-0.17(0.27)$ & $(-0.29,-0.04)$ \\
\hline \multicolumn{5}{|c|}{ Maximum reading speed (words per minute) } \\
\hline \multicolumn{5}{|l|}{ No $(n=24)$} \\
\hline Median (IQR) & $150(123,196)$ & $130(68,184)$ & & \\
\hline Mean (SD) & $153.2(52.2)$ & $123.9(66.3)$ & $-29.3(54.87)$ & $(-52.5,6.1)$ \\
\hline \multicolumn{5}{|l|}{ Yes $(n=20)$} \\
\hline Median (IQR) & $126.5(82,167)$ & $187(143,200)$ & $41.6(43.0)$ & $(21.5,61.7)$ \\
\hline Mean (SD) & $126.9(52.4)$ & $168.5(56.4)$ & & \\
\hline
\end{tabular}

VIEW 2 trials respectively [1]. Swept-source (Topcon DRI) OCT-derived choroidal thickness at the end of year 1 was reduced by $29.2 \mu \mathrm{m}$ or by $14 \%$, which is comparable to the $11 \%$ reduction of choroidal thickness both in typical AMD and PCV found in Ting et al.'s study in a series of 163 patients with a higher proportion of PCV eyes and a younger age average than in our series [15].

There are recent studies where choroidal thickness change was evaluated using EDI (enhanced depth imaging) OCT, with a much shorter-term follow-up time or a lower number of participants $[16,17]$ and studies where measurement of choroidal thickness was performed using Spectralis OCT, after only a loading dose of intravitreal injection treatment [18]. The current study is, to the best of our knowledge, the only prospective study with in which sweptsource OCT imaging has been used to assess the impact of anti-VEGF treatment on central macular choroidal thickness in nAMD. The reduction in choroidal thickness with antiVEGF treatment has been previously described in the studies mentioned above in one of which there was no impact of the number of anti- 
VEGF injections on the degree of reduction in choroidal thickness [17]. Note that a recent study suggested that an increase in choroidal thickness in nAMD eyes undergoing anti-VEGF therapy may be a novel biomarker of disease activity [19].

In this study, in addition to traditional OCT end points (changes in macular retinal and choroidal thickness), additional OCT-based morphological features of nAMD were analysed to explore how these changed with aflibercept treatment over 2 years: reduction in the maximum PED height was expected and was in accordance with a previous study [20]. The proportion of cases of PCV diagnosed with ICG was $14 \%$ in our study, in which the majority of our patients were white women with a mean age of 78 years, higher than the pooled prevalence of PCV in white patients with exudative AMD which was $8.7 \%$ in Lorentzen et al.'s recent systematic review and meta-analysis [21]. The proportion of type III neovascularization (RAP) was $12 \%$, comparable to the $10.7 \%$ found in the Age-related Macular Degeneration Treatment Trials (CATT) [22]. The presence of SRHM was also recorded both at baseline and at the end of year 2. It was detected in $80 \%$ of our cases at baseline and it was found in only $14 \%$ of the eyes included in our analysis at year 2 . Reduction in the proportion of cases of nAMD with SRHM has been noted before [23] but the proportion of patients who had no SRHM at the end of follow-up was higher in our series. In older studies, presence and persistence of SRHM was related to poor vision [24]. In Kawashima et al.'s study, in which aflibercept was the treating anti-VEGF agent, they categorized SRHM as vascular and avascular using quantitative OCT angiography (OCTA) analysis and they concluded that vascular SHRM is predictive of lower response to anti-VEGF therapy after three aflibercept injections [25]. Although the VITAL study predated the introduction of OCTA imaging and we were therefore unable to distinguish between vascular and avascular SRHM, we were able to evaluate the long-term impact of aflibercept treatment on SHRM in nAMD eyes. Our results suggest that an optimal visual outcome may be related among other parameters to the absence of SRHM achieved with a treat-and-extend treatment regimen with aflibercept during the second year of treatment.

We also aimed to look at the association between the presence or absence of macular fluid with BCVA change and reading acuity as well as reading speed change at the end of year 2. Mean change in BCVA was similar in the presence and in the absence of fluid at year 2 . Interestingly, reading speed and reading acuity were found to be better in eyes for which fluid was still present on OCT. As a result of our limited sample size, we did not attempt to attribute statistical significance to the outcomes above and further studies are needed to robustly evaluate the association between macular fluid and reading outcomes. One plausible explanation for an association between absence of macular fluid at 2 years and poorer reading ability is that absence of macular fluid has been associated with macular atrophy. Macular atrophy in turn may have a disproportionate effect on reading metrics (particularly reading speed) compared to tasks which rely more heavily on foveal function (visual acuity testing). Worsening in reading performance with stable visual acuity could therefore indicate the impact of macular atrophy on vision function though exploring this potential association was outside the scope of this study.

The strengths of the study included the standardised treatment paradigm, focus on reading-related metrics and assessment of a wide range of OCT retinal morphological features over 2 years of treatment. Weaknesses include the limited sample size and the noncomparative nature of the study.

\section{CONCLUSIONS}

The VITAL study evaluated the impact of aflibercept treatment of $\mathrm{nAMD}$ on both reading performance and an extended range of macular morphological treatment outcomes. Our study shows that sustained improvements in reading performance, visual acuity and in retinal morphology can be achieved using aflibercept treatment for nAMD with fixed dosing in the first year of treatment followed by a treat-andextend approach to treatment in year 2 . 


\section{ACKNOWLEDGEMENTS}

The authors would like to thank Nicola Harris, Bharti Arya, Marko Lukic, Wen Xing, Catherine Grigg, Ioanna Triantafyllopoulou, Mahdi Muwas of NIHR Biomedical Research Centre at Moorfields Eye Hospital NHS Foundation Trust and UCL Institute of Ophthalmology, London, UK for their hard work and valuable contribution in the management and delivery of this study.

Funding. The research was funded by Bayer UK and supported by the NIHR Biomedical Research Centre at Moorfields Eye Hospital NHS Foundation Trust and UCL Institute of Ophthalmology and the NIHR Moorfields Clinical Research Facility. The views expressed are those of the author(s) and not necessarily those of the NHS, the NIHR or the Department of Health. No funding or sponsorship was received for the publication of this article.

Authorship. All named authors meet the International Committee of Medical Journal Editors (ICMJE) criteria for authorship for this article, take responsibility for the integrity of the work as a whole, and have given their approval for this version to be published.

Disclosures. Hari Jayaram, Maria Eleftheriadou, Clara Vazquez-Alfageme, Bishwanath Pal, Peter K Addison and Gary S Rubin have nothing to disclose. Niaz Islam has received personal fees from Bayer UK (lecturing, educational travel grant, advisory board). Praveen J Patel has received personal fees from Bayer UK and Novartis UK (lecturing, educational travel, advisory board). Praveen J Patel is also a member of the journal's Editorial Board. Robin Hamilton has received personal fees from Bayer UK and Novartis UK (lecturing, educational travel grant, advisory board). Simona Degli Esposti received personal fees from Bayer UK (educational travel grant) and Novartis UK (lecturing fees).

Compliance with Ethics Guidelines. This study was conducted in accordance with the tenets of the Declaration of Helsinki and ethics approval was obtained from the NRES (National Research Ethics Service) Committee London Fulham (approval number 14/LO/1561; EudraCT number 2014-002381-73). Although patients were not directly involved in the development of the research study, the objectives of the VITAL study are aligned with the research uncertainties identified by the James Lind Alliance Sight Loss and Vision Priority Setting Partnership workshop. This was a singlecentre study conducted at Moorfields Eye Hospital NHS Foundation Trust. All participants provided written informed consent.

Data Availability. De-identified participant data are available from the corresponding author on reasonable request. Reuse of data is permitted if the VITAL study is acknowledged and referenced accurately.

Open Access. This article is licensed under a Creative Commons Attribution-NonCommercial 4.0 International License, which permits any non-commercial use, sharing, adaptation, distribution and reproduction in any medium or format, as long as you give appropriate credit to the original author(s) and the source, provide a link to the Creative Commons licence, and indicate if changes were made. The images or other third party material in this article are included in the article's Creative Commons licence, unless indicated otherwise in a credit line to the material. If material is not included in the article's Creative Commons licence and your intended use is not permitted by statutory regulation or exceeds the permitted use, you will need to obtain permission directly from the copyright holder. To view a copy of this licence, visit http:// creativecommons.org/licenses/by-nc/4.0/.

\section{REFERENCES}

1. Schmidt-Erfurth U, Kaiser PK, Korobelnik JF, et al. Intravitreal aflibercept injection for neovascular age-related macular degeneration: ninety-six-week results of the VIEW studies. Ophthalmology. 2014;121(1):193-201. https://doi.org/10.1016/j. ophtha.2013.08.011. 
2. Wykoff CC, Ou WC, Croft DE, et al. Neovascular age-related macular degeneration management in the third year: final results from the TREX-AMD randomised trial. Br J Ophthalmol. 2018;102(4): 460-4. https://doi.org/10.1136/bjophthalmol2017-310822.

3. DeCroos FC, Reed D, Adam MK, et al. Treat-andextend therapy using aflibercept for neovascular age-related macular degeneration: a prospective clinical trial. Am J Ophthalmol. 2017;180:142-50. https://doi.org/10.1016/j.ajo.2017.06.002.

4. Barthelmes D, Nguyen V, Daien V, et al. Two year outcomes of "treat and extend" intravitreal therapy using aflibercept preferentially for neovascular agerelated macular degeneration. Retina. 2017. https:// doi.org/10.1097/IAE.0000000000001496.

5. Mrejen S, Jung JJ, Chen C, et al. Long-term visual outcomes for a treat and extend anti-vascular endothelial growth factor regimen in eyes with neovascular age-related macular degeneration. J Clin Med. 2015;4(7):1380-402. https://doi.org/10. $3390 /$ jcm4071380.

6. Eleftheriadou M, Vazquez-Alfageme C, Citu CM, et al. Long-term outcomes of aflibercept treatment for neovascular age-related macular degeneration in a clinical setting. Am J Ophthalmol. 2017;174: 160-8. https://doi.org/10.1016/j.ajo.2016.09.038.

7. McClure ME, Hart PM, Jackson AJ, Stevenson MR, Chakravarthy U. Macular degeneration: do conventional measurements of impaired visual function equate with visual disability? Br J Ophthalmol. 2000;84(3):244-50.

8. Bullimore MA, Bailey IL, Wacker RT. Face recognition in age-related maculopathy. Invest Ophthalmol Vis Sci. 1991;32(7):2020-9.

9. Hazel CA, Petre KL, Armstrong RA, Benson MT, Frost NA. Visual function and subjective quality of life compared in subjects with acquired macular disease. Invest Ophthalmol Vis Sci. 2000;41(6): 1309-15.

10. Elliott DB, Trukolo-Ilic M, Strong JG, Pace R, Plotkin A, Bevers P. Demographic characteristics of the vision-disabled elderly. Invest Ophthalmol Vis Sci. 1997;38(12):2566-75.

11. Rae S, Latham K, Katsou MF. Distance word acuity, critical print size and driving vision standards. Clin Exp Optom. 2015;98(5):459-63. https://doi.org/10. 1111/cxo.12292.

12. Patel PJ, Chen FK, da Cruz L, Rubin GS, Tufail A. Test-retest variability of reading performance metrics using MNREAD in patients with age-related macular degeneration. Invest Ophthalmol Vis Sci. 2011;52(6):3854-9.

13. Rubin GS. Measuring reading performance. Vis Res. 2013;90:43-51. https://doi.org/10.1016/j.visres. 2013.02.015.

14. Epstein D, Amren U. Near vision outcome in patients with age-related macular degeneration treated with aflibercept. Retina. 2016;36(9):1773-7. https://doi.org/10.1097/IAE.0000000000000978.

15. Ting DS, Ng WY, Ng SR, et al. Choroidal thickness changes in age-related macular degeneration and polypoidal choroidal vasculopathy: a 12-month prospective study. Am J Ophthalmol. 2016;164: 128-36e1. https://doi.org/10.1016/j.ajo.2015.12. 024.

16. Gharbiya M, Giustolisi R, Marchiori J, et al. Comparison of short-term choroidal thickness and retinal morphological changes after intravitreal antiVEGF therapy with ranibizumab or aflibercept in treatment. Curr Eye Res. 2018;43(3):391-6. https:// doi.org/10.1080/02713683.2017.1405045.

17. Kaya F. Change in choroidal thickness after intravitreal injection for treatment of neovascular age-related macular degeneration: ranibizumab versus aflibercept. J Fr Ophtalmol. 2017;40(10): 832-8. https://doi.org/10.1016/j.jfo.2017.04.014.

18. Mazaraki K, Fassnacht-Riederle H, Blum R, Becker $\mathrm{M}$, Michels S. Change in choroidal thickness after intravitreal aflibercept in pretreated and treatmentnaive eyes for neovascular age-related macular degeneration. $\mathrm{Br} \mathrm{J}$ Ophthalmol. 2015;99(10): 1341-4. https://doi.org/10.1136/bjophthalmol2015-306636.

19. Tan CS, Cheong KX, Lim LW, Sadda SR. Comparison of macular choroidal thicknesses from swept source and spectral domain optical coherence tomography. Br J Ophthalmol. 2016;100(7):995-9. https://doi.org/10.1136/bjophthalmol-2015307541.

20. Cho HJ, Kim KM, Kim HS, Lee DW, Kim CG, Kim JW. Response of pigment epithelial detachment to anti-vascular endothelial growth factor treatment in age-related macular degeneration. Am J Ophthalmol. 2016;166:112-9. https://doi.org/10.1016/ j.ajo.2016.03.039.

21. Lorentzen TD, Subhi Y, Sorensen TL. Prevalence of polypoidal choroidal vasculopathy in white patients with exudative age-related macular degeneration: systematic review and meta-analysis. Retina. 2018;38(12):2363-71. https://doi.org/10. 1097/IAE.0000000000001872. 
22. Martin DF, Maguire MG, Ying GS, Grunwald JE, Fine SL, Jaffe GJ. Ranibizumab and bevacizumab for neovascular age-related macular degeneration. N Engl J Med. 2011;364(20):1897-908.

23. Daniel E, Shaffer J, Ying GS, et al. Outcomes in eyes with retinal angiomatous proliferation in the comparison of age-related macular degeneration treatments trials (CATT). Ophthalmology. 2016;123(3): 609-16. https://doi.org/10.1016/j.ophtha.2015.10. 034.
24. Pokroy R, Mimouni M, Barayev E, et al. Prognostic value of subretinal hyperreflective material in neovascular age-related macular degeneration treated with bevacizumab. Retina. 2018;38(8):1485-91. https://doi.org/10.1097/IAE.0000000000001748.

25. Kawashima Y, Hata M, Oishi A, et al. Association of vascular versus avascular subretinal hyperreflective material with aflibercept response in age-related macular degeneration. Am J Ophthalmol. 2017;181:61-70. https://doi.org/10.1016/j.ajo. 2017.06.015. 